\title{
Challenges in Life Cycle Assessment (LCA) of stabilised clay-based construction materials
}

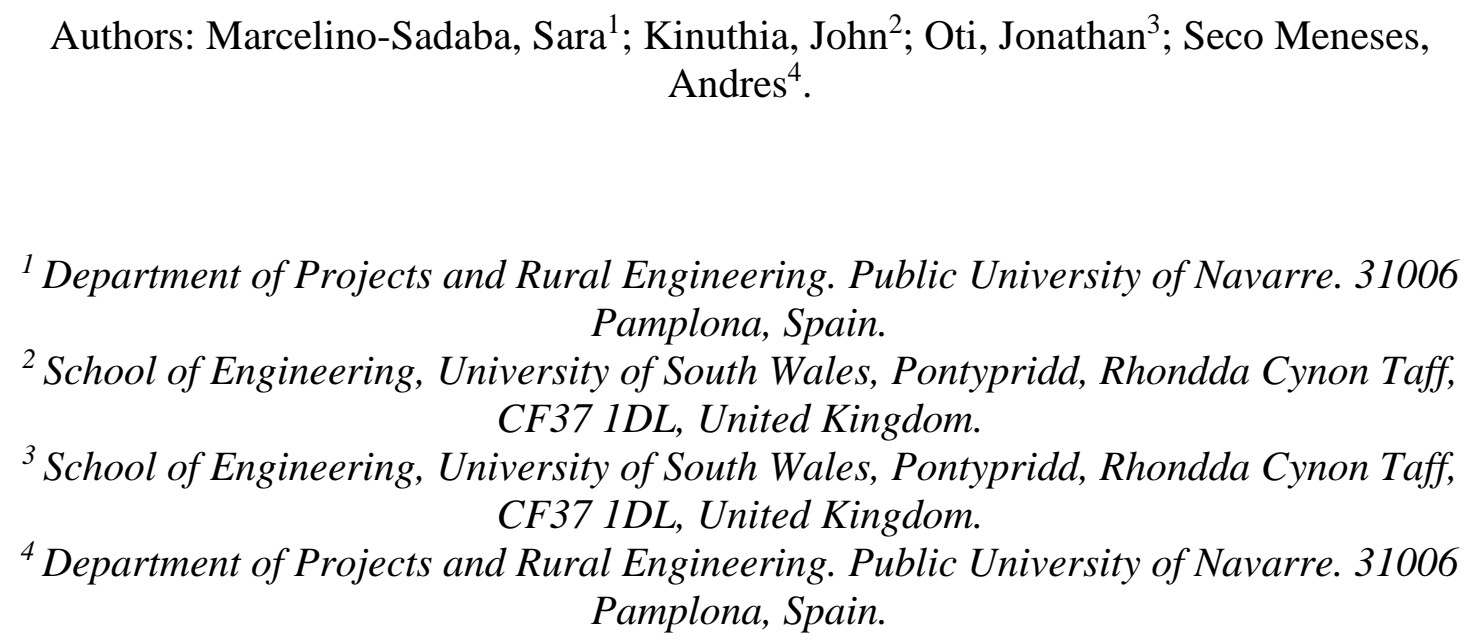

(C) 2017. This manuscript version is made available under the CC-BY-NC-ND 4.0 license http://creativecommons.org/licenses/by-nc-nd/4.0/

${ }^{1}$ Corresponding author(E-mail: $\underline{\text { sara.marcelino@unavarra.es) }}$ 

materials

\begin{abstract}
The preference of clay-based materials for sustainable construction is well-established. The establishment of sustainability credentials of emergent construction materials is very subjective, and most available tools are not fully equipped to deal with individual material systems, such as composite cement- or lime-based cementitious systems, including clay-based blocks and bricks. The main problem emanates from the challenges of the audit of each aspect of the material processing, and especially the quantification of the most relevant inputs into the composite product. The variability in material ingredients, and lack of data for each aspect of the manufacturing processes involved creates major challenges. Incorporation of materials with long and complex recycling processes further exacerbate the challenge. These incorporations create problems in terms of accurate material trails and data for input in a robust Life Cycle Assessment (LCA) of individual products. This paper reports on a simplified approach towards full LCA of seven clay-based brick products developed in UK (4) and Spain (3), based on known material data and estimated energy inputs in the manufacturing processes. The UK-based bricks comprise of Lower Oxford Clay (LOC), stabilised using combinations of hydrated lime, Ground Granulated Blast-furnace Slag (GGBS) and Portland cement (PC). In order to test the robustness of the proposed approach, results on UK-based bricks are compared with a parallel LCA on clay-based product developed in Spain. Finally, the clay-based products are compared with a typical Portland cement-based concrete block and fired clay brick. In the LCA, boundary conditions include fixed transport, thus attempting to factor only the material ingredients, their known atmospheric emissions, and estimated energy inputs during processing. Results suggest that the most challenging aspect in the undertaking of LCA is the availability of reliable input data. Results also show that there are numerous parameters that can reliably and corroboratively facilitate the comparison of performance, besides carbon dioxide emissions.
\end{abstract}

Keywords: clay, life cycle analysis, stabilisation, soil, cementation, sustainability

\title{
1 INTRODUCTION
}

Sustainability is a complex term to define in a sufficiently or practical way so as to make it operative and there are wide-ranging insights into sustainability and its practices (Marcelino-Sádaba et al., 2015). It is a holistic, ambiguous, forward-thinking, global and normative concept. There have been attempts to achieve complex meshed tools for the assessment of sustainability, by using the many constituent characteristics of sustainability (Pope, 2006).

With these difficulties in definition and differences in perception, the Kyoto Protocol (1995) has resulted in pressure on societies, through respective governments, to have enhanced concern for the environment and in a large number of initiatives and programs aimed at reducing the effects of human activities on the environment. The construction 
With concrete being the third most used substance in the world after air and water, attention has quickly turned to soil-based materials for applications that do not necessarily warrant excessively strong binding. Soil stabilisation involves the utilisation of chemical binders such as lime and/or Portland cement, whose manufacture consumes large quantities of precious natural raw material resources and energy, and has other negative impact. The manufacture of modern Portland cement for example produces $600-1000 \mathrm{~kg}$ of atmospheric $\mathrm{CO}_{2}$ per tonne of cement produced, depending on production process, accounting for at least $5 \%$ of man-made $\mathrm{CO}_{2}$ emission in the atmosphere (The European Cement Association, 2013).

Life Cycle Assessment (LCA) is one of the most used methods for evaluating a product's impact on the environment over its entire lifespan. The LCA method was developed to analyse the resources extracted and quantify the emissions related to a product over its entire life cycle (JRC European commission, 2011). The main characteristics of a LCA approach are that it includes a wide range of different environmental problems such as climate change, toxic effects, material and land resource depletion, and it has a holistic character which prevents the transfer of the environmental problem, and also prevents the solution of a particular problem deteriorating elsewhere in the lifecycle.

LCA provides valuable information that allows managers to make decisions aimed at improving the environmental performance of their products and/or services (Hossain et al., 2016). Although LCA is not aimed at individual material products, it still remains useful as a tool for environmental management, since it facilitates the identification of the source of a potential problem or concern, optimize resource use and manage waste produced, thus contributing to the decision making process between different sustainable materials (Chen et al., 2010b).

When performing LCA, it is important and helpful to follow the international standard ISO 14040-series, especially when a company uses an LCA externally (ISO, 2007, 2006a, 2006b). Based on these standards, The International Reference Life Cycle Data System (ILCD) Handbook (JRC European commission, 2011) provides recommendations on models and characterization factors that should be used for impact assessment in applications such as LCA. 
In LCA methodology applied to products that include recycling materials, the most important decision is how to consider the environmental output of these materials. According to the new EU directive (EU, 2008) some waste should be now considered as by-products and thus be affected by an allocation coefficient (Chen et al., 2010b; Gala et al., 2015). There is an open discussion about the allocation process and new methods based on the market price of products and by-products are arising (Schrijvers et al., 2016a, 2016b). However, when developing new sustainable materials, the origin of these inputs are not usually known, and for that reason one approach is set boundary conditions, enabling the consideration of only the processes that are needed to transform the inputs (Chen et al., 2010b).

A big effort is being made in the search for new environmental-friendly materials through research and development activities in different areas such as i) raw material substitution, ii) clinker substitution, iii) low carbon concrete production and iv) recycling concrete among others, in order to meet target $\mathrm{CO}_{2}$ emissions (Habert et al., 2011; Tait and Cheung, 2016). There is potential inherent in industrial waste and by-product materials with embodied energy, such as Pulverised Fuel Ash (PFA or of fly ash) from the burning of coal, and ground granulated blastfurnace slag (GGBS) from steel manufacture, for exploitation in order to reduce consumption of Portland cement, and hence reduce the emissions (Flower and Sanjayan, 2007; Habert et al., 2011; Tait and Cheung, 2016). In addition, the preference of clay-based materials for sustainable construction has increased.

In the search for more sustainable materials in order to meet global emission targets, numerous tools for the establishment and assessment of sustainability credentials of emergent construction materials have mushroomed. The advocacy for each tool has resulted in very subjective tools being available tools such BREEAM, LEED, ATHENA, CEQUAL, SpeAR among others. These tools are not equipped to deal with individual material systems, such as individual composite cement- or lime-based cementitious systems, including clay-based blocks and bricks. Mainly used for the rating of the environment credentials of master plans, one of the world leading tools developed in UK, BREEAM (Building Research Establishment Environmental Assessment Methodology) does not assess individual building units for buildings and infrastructure. CEEQUAL (Civil Engineering Environmental Quality) is another UK-developed award scheme that 
breaks down the three pillars of sustainability - social, economic and environment - to rate entire projects in a 10-step process to arrive at a pass, good, very good or excellent rating. In-house tools are not necessarily any easier. For example, ARUP's SPeAR (Sustainable Project Appraisal Routine) uses about 23 steps. Other more laborious tools include ENVISION, developed in the US and uses about 60 sustainability criteria. There is therefore very little research devoted to approaches for rating or assessing individual materials systems

In the detailed assessment of individual materials systems or products, the main challenge results from the accurate audit of each aspect of the material processing, and especially the quantification of the relevant transport, energy, environmental (emissions) and the many other inputs into the sustainable product. There are however pockets of information, especially on embodied carbon, available depending on individual awareness of its availability. In the UK, Jacobs Ltd. have detailed data on embodied carbon of different materials for pipework. At the University of Bath, there is an inventory of embodied energy of about 200 different civil engineering materials (Hammond \& Jones, 2008).

Not all the available data is in agreement. Also, the variability in material ingredients, poses a significant challenge, together with the lack of key data for each material ingredients, especially for the emergent wide range of recycled materials. Key data such as on energy consumption and tally of emissions during production, creates major challenges. Incorporation of materials with a long history of processing during recycling further exacerbates the challenge. For example, the variable sourcing and complex recycling processes involved in the recycling of waste from plastics, tyres, glass, among other recyclables, sometimes creates unsurmountable challenges.

There is need to start developing widespread and more accurate or agreed material trails and data for input for pragmatic and robust whole life cycle analyses (LCAs) of individual products. This is more critical for composite materials that incorporate non-traditional constituents such as recycled wastes and by-products. Such emergent LCA approaches could help to facilitate the comparison of different alternatives for individual materials and products, for a global rating or point of view. These new LCA analyses could be devolved or simplified into generically agreed steps (LCA(I), LCA(II) etc.). For example, LCA(I) could be made, and generally agreed, to only refer to materials development from 
cradle to gate approach (See Figure 1). The results of LCA(I) could be used as input in further LCAs if necessary. Extension of data would lead to the next phases such as uptake for building construction and exploitation (cradle to grave) (LCA(II)) and even to the end of life phase (LCA(III) and materials recycling phase (cradle to cradle) (LCA(IV).

\section{Figure 1}

A few researchers have indirectly recognised the benefits of simple or devolved assessment tools as in enabling practitioners to obtain better selection criteria between different materials (Chen et al., 2010a). This paper reports on such a devolved approach towards LCA. The approach analyses three clay-based brick products developed in Pamplona, Navarre, Spain, based on known material data and estimated energy inputs in the manufacturing process. In order to test the robustness of the proposed approach, results are compared with four other clay-based products developed in the United Kingdom. Results suggest that it is possible to adopt and/or aim for a multi-pronged result in the undertaking of a holistic and meaningful LCA, rather than adopting a single parameter approach or consensus.

\section{MATERIALS}

Seven clay-based products were selected for LCA, based on the authors' knowledge of not only their exact compositions but also of the basic information regarding their constituent ingredients. This knowledge is critical for a meaningful LCA. In addition, the awareness of the performance in terms of mechanical or other properties is essential, for the assessment of the likelihood and degree of success of their application, as well as for normalization of comparisons.

The three Spanish brick products all comprised of a marl target soil. This is a soft graycolored fine clay soil where XRD analysis showed a mineralogical composition of $51 \%$ calcite, $20 \%$ illite, $15 \%$ quartz, $5 \%$ kaolinite, $5 \%$ attapulgite and $4 \%$ ankerite (Seco et al., 2011). The soil was stabilised using three alternative cementitious additives, i) Portland cement, ii) a blended binder comprising of hydrated lime (CL-90-S) and GGBS, and iii) Magnesium Oxide combined with GGBS. The magnesium oxide was obtained as a commercial industrial by-product (PC-8), produced as a waste from the industrial 
204

205

206

207

208

209

210

211

212

213

214

215

216

217

218

219

220

221

222

223

224

225

226

227

228

229

230

231

232

233

234

235

236

237

calcination of natural magnesite at $1100^{\circ} \mathrm{C}$ (Seco et al., 2011). The properties of the binders in the various clay products from Spain are shown in Table 1, while the mix designs for both Spain- and UK-based products are summarized in Table 2.

\section{Table 1}

Table 2

The four clay-based products developed in the United Kingdom (see Table 1) all targeted Lower Oxford Clay (LOC). It was supplied by Hanson Brick Company Ltd., from their Stewartby fired brick plant in Bedfordshire, UK. The composition of the LOC includes 23\% illite, 10\% kaolinite, 7\% Chlorite, 10\% Calcite, 29\% Quartz, 2\% Gypsum, 4\% Pyrite, $8 \%$ Feldspar and 7\% Organic material (Oti et al., 2008, 2009). The particle size distribution of the LOC is shown in Table 3.

\section{Table 3}

The LOC was stabilised using i) Hydrated lime, ii) Lime-GGBS blend, and iii) Portland cement, and iv) Portland cement-GGBS blend. The lime used was quicklime (calcium oxide), and was manufactured and supplied by Ty-Mawr Lime Ltd, Llangasty, Brecon, UK. Portland Cement (PC), manufactured in accordance with BS EN 197-1, 2000, and supplied by Lafarge Cement UK, was used throughout this work. The GGBS used was in compliance with BS EN, 15167-1, 2006 and was supplied by Civil and Marine Ltd, Llanwern, Newport, UK. For LOC and all these additives, Table 4 shows their oxide compositions while Table 5 shows some of the known physical properties.

Table 4

\section{Table 5}

For the concrete block used as control, data available in ELCD data base (ELCD 2016) show its main ingredients as being quartz sand (60 to 70\%), cement (type CEMI) (20 to $30 \%$ ), quick lime (10 to $20 \%$ ), and gypsum (2 to $5 \%$ ). The mineral residue is considered to be about $3.5 \%$, and for LCA purposes may be handled as inert waste, reusable in the 
building industry. As an additional reference point, a fired brick has been included, and base data on energy production obtained in the authors' previous publications (Oti and Kinuthia, 2012).

\section{METHODOLOGY}

The environmental impact evaluation of the Spain-based and UK-based clay bricks was carried out by a LCA approach using an Open access software 'Open LCA' using the European reference Life Cycle Database (ELCD) that provides Life Cycle Inventory (LCI) data from EU-level business associations and other sources for key materials, energy carriers, transport, and waste management. The environmental impacts were evaluated according to the baseline method of CML01 (Guinée et al., 2002) that analyses 10 environmental impacts (abiotic depletion, global warming, ozone layer depletion, fresh and marine water ecotoxicity, terrestrial ecotoxicity, human toxicity, eutrophication, acidification and photochemical oxidation). Among these categories, four of them have the greatest environmental impact: i) Global warming (due to the $\mathrm{CO}_{2}, \mathrm{CO}, \mathrm{CH}_{4}$ emissions), ii) Acidification and iii) Eutrophication (due to $\mathrm{SO}_{2}, \mathrm{NH}_{3}$, and $\mathrm{NOx}$ emissions), and iv) Human toxicity (due to dust and $\mathrm{SO}_{2}$ emissions). Using these impacts, four phases of assessment adopted in ISO 14044 (2006) framework were used: 1) Goal and scope definition, 2) Inventory assessment, 3) Impact assessment and 4) Results interpretation.

\subsection{Goal and scope}

The main goal of this study was to quantify the environmental impact of different claybased construction materials, and to compare them with one clay-based and one non-clay based material. In order to avoid the complications of recycling a multi-ingredient product, with some of the ingredient being recycled themselves, cradle-to-gate LCA approach (that ends with production) was applied as shown in Figure 2. This simplified approach involves the journey from resources to the product stage, and needs taking out distribution, use and end of life issues in two different countries (UK and Spain). In addition, the following assumptions were taken into account:

1. A baseline target processing of 1 tonne of final product.

2. As this study includes materials from different countries (UK and Spain), no transport-based emissions were considered. 
3. As all the products do not have equivalent mechanical performance and durability, a baseline performance rating based on the impact per unit strength gained (normalisation) was adopted

Figure 2

\subsubsection{Inventory analysis}

The LCI for the materials are based on CEMBUREAU, 2015; Habert et al., 2011; and on Oti and Kinuthia, 2012, and data extracted from the European Life Cycle Database (ELCD) accessed on 26/09/2016. When no detailed data about materials input are known, the input considered has been the energy needed for its production. The inventory data on energy needed for production is shown in Table 6.

Table 6

- For energy, the data set represents the average specific electricity consumption during production. Main technologies for combustion, flue gas cleaning and electricity generation are considered according to the national or region specific situation.

- For Portland cement Data are based on cement plants which are representative for CEMBUREAU member countries.

- The brick production process includes the crushing of the clay, the mixing of all components and the compression to make the bricks. Power data are based on a mobile machinery from the Belgian company APPRO-TECHNO, S.A., so as to achieve commonality and an analysis that is independent of brick making facilities.

\subsubsection{Impact assessment}

The environmental impact evaluation of the Spain-based and UK-based clay products was carried out by a LCA approach using an Open access software 'Open LCA' using the European reference Life Cycle Database (ELCD) that provides Life Cycle Inventory (LCI) data from EU-level business associations and other sources for key materials, energy carriers, transport, and waste management. The environmental impacts were evaluated according to the baseline method of CML01 (Guinée et al., 2002) that analyses 10 environmental impacts (abiotic depletion, global warming, ozone layer depletion, fresh and marine water ecotoxicity, terrestrial ecotoxicity, human toxicity, eutrophication, acidification and photochemical oxidation). Among these categories, four of them have 
the greatest environmental impact: Global warming (due to the $\mathrm{CO}_{2}, \mathrm{CO}, \mathrm{CH}_{4}$ emissions), Acidification and eutrophication (due to $\mathrm{SO}_{2}, \mathrm{NH}_{3}$, and $\mathrm{NOx}$ emissions) and ozone layer depletion.

Normalisation is a procedure that is an optional step in LCA (ISO, 2006). This was made in the current analysis, so that different impact parameters could be standardised and a near global evaluation for each product could achieved. This normalisation allowed the comparison of the different materials. The normalization was based on the relationship between the emissions of the materials and the impact from all activities of a European citizen during one year.

\section{Results \& Discussion}

\subsection{Compressive strength}

Figure 3 shows the raw compressive strength data of the various brick or block products under investigation. The three marl-based bricks made in Spain had superior compressive strength within 10-14 MPa. In contrast, the four UK-based products based on LOC were within 4-8 MPa. In both UK and Spanish products, the highest strength values were recorded with the GGBS-containing products. The UK team set its target compressive strength based on the strength of the minimum design compressive strength values mentioned in the British Standard for concrete masonry units $-2.8 \mathrm{~N} / \mathrm{mm}^{2}$ for blocks and $7 \mathrm{~N} / \mathrm{mm}^{2}$ for bricks (BS 6073-2:2008). The equivalent strength referred to for fired clay units is far higher, being a minimum of $75 \mathrm{~N} / \mathrm{mm}^{2}$ for clay engineering bricks Class $\mathrm{B}$, and $125 \mathrm{~N} / \mathrm{mm}^{2}$ for Class A (BS EN 771-1:2011). The Spanish team did not work to any known target strength, and aimed at maximal strength achievable using the target materials and what they considered reasonable binder content range. The current work therefore selected mix formulations that are of comparable binder content levels of 8-10\% replacement level for both lime- and PC-based formulations. It is because of the resultant strength differences that all impact parameters were normalised, so as to evaluate impact per unit strength gain.

\section{Figure 3}


The raw results of the LCA are shown in Table 7. Based on the various compressive strength values, the raw LCA data was normalised in order to show impact per unit strength. The normalised data are shown at the bottom half of Table 7. Six parameters in Table 7 that were considered representative of typical impact were selected to facilitate the comparison between Spain- and UK-based products, relative to two common materials controls, i) a typical high density concrete block (CB) and ii) a typical fired clay brick (FCB). The selected parameters (highlighted in Table 7) are acidification potential $\left(\mathrm{SO}_{2}\right)$, climate change $\left(\mathrm{CO}_{2}\right)$, depletion of fossil fuels $(\mathrm{MJ})$, eutrophication $\left(\mathrm{PO}_{4}\right)$, depletion of the ozone layer depletion (CFC), and terrestrial ecotoxicity (equivalent 1, 4 dichlorobenzene).

\section{Table 7.}

\subsection{Acidification potential ( $\mathrm{SO}_{2}$ eq. $)$}

Acidification is associated with the increase of heavy metals in solid, and surface waters, and hence in plants, and is associated with pollutant components. It is assessed with reference to $\mathrm{SO}_{2}$. The known acidification potential of a selected sample of substances is illustrated in Table 8. For the materials under investigation, Figures 4(a) and (b) show the absolute acidification impacts ( $\mathrm{kg} \mathrm{SO}_{2}$ eq.) and the relative values per unit strength respectively, for the different products. Absolute acidification emanating from the concrete block (CB) is the most significant, followed by the $\mathrm{Mg}$-containing product from the Spanish products range (Fig 4(a)). However, when the strength results are factored, the high strength of the Mg-based product favours the outcome, and the most concerning product is the UK-product made using clay and lime (without GGBS). Although the absolute acidification of this product is moderate (Fig 4(a), it shows worse outcome relative to the two controls ( $\mathrm{CB}$ and FCB) due to the superior strength performance of the latter. It is therefore preferable to replace some of the lime using GGBS during soilstabilisation (as suggested by test results or both marl and LOC), for all-round good performance and environmental friendliness.

\section{Figure 4 (a) and (b)}

\subsection{Climate change $\left(\mathrm{CO}_{2}\right.$ eq. $)$}


Figures 5 (a) and (b) show the effects of climate change based on equivalent $\mathrm{CO}_{2}$ from

Figure 5 (a) and (b)

\subsection{Depletion of fossil fuels (MJ)}

The consumption of precious natural raw materials resources is a major concern and consideration in the realisation of economic development. Figures 6 (a) and (b) give an indication of the depletion of fossil fuels in the manufacture of 1 tonne of the cementitious products developed in both Spain and UK in the current research study. It is reassuring to note that in both absolute and relative terms, the control traditional products (concrete block and the energy intensive fired clay brick both show highest depletion levels. Of the researched products, highest depletion was shown by the use of LOC with lime (LOCLime). This was mitigated by replacing some of the lime with GGBS in LOC-LimeGGBS, which performed better than LOC-PC per unit strength achieved (Fig 6(b). All the Spanish products performed very well both in absolute terms (Fig 6 (a)) as well as per unit strength achieved (Fig 6(b)). The differences between the well-performing Spanish and UK products is thought to be due to minor differences in processing stage (see Figure 2). For this reason, the data presented should be aimed and interpreted to as showing the most obvious differences, and minor differences between trends/products should either be ignored and/or interpreted with caution.

Figure 6 (a) and (b) 


\subsection{Eutrophication ( $\mathrm{PO}_{4}$ eq.)}

405

406

407

408

409

410

411

412

413

414

415

416

417

418

419

420

421

422

423

424

425

426

427

428

429

Eutrophication is a measure of the depletion of oxygen in water masses. This can be caused by unwanted growth in water masses due to provision nutrients. The decay of biomass consumes dissolved oxygen, and thus negatively impacting on aquatic lifeforms. Excess nutrients can be produced from sources of excess phosphates, and thus eutrophication is commonly assessed by monitoring the levels of residual equivalent phosphate ( $\mathrm{PO}_{4}$ eq.). Industrial run-off can be a contributor to eutrophication, and thus monitoring $\mathrm{PO}_{4}$ levels can provide a tool for the assessment of whole life cycle environmental impact of industrial activities such as material manufacture as in the current research study. Figures 7 (a) and (b) show the eutrophication levels resulting from the assessment of the Spain- and UK-researched products, relative to the two control products of concrete block and fired clay brick. The UK-based products made using the traditional binders of lime and Portland cement were observed to show highest levels of eutrophication per unit strength (Fig 7(b)). Incorporation of GGBS mitigated this negative effect. The concrete block and fired clay brick showed low eutrophication levels, due to their higher strength development and hence superior binding of phosphates.

Figure 7 (a) and (b)

\subsection{Ozone layer depletion (CFC e.q.)}

Depletion of the ozone layer is associated with global warming, due to the accumulation of greenhouse gas (GHG) effect. The GHG gases are established relative to the much more polluting, but less prevalent, chloro-fluoro carbons (CFCs). Figures 8 (a) and (b) show the indicative effects of the researched products on the ozone layer depletion, relative to the damage by the concrete block and fired clay bricks. Once again products incorporating GGBS showed best performance, which was further enhanced by addition of the $\mathrm{MgO}$ industrial waste. Use of lime or PC on their own as binder materials showed worst performance. This confirms the now well-establish fact that traditional binders, particularly Portland cement, is very damaging to the atmosphere.

Figure 8 (a) and (b) 


\subsection{Terrestrial ecotoxicity ( $k g$, 4, dichlorobenzene eq.)}

Toxins are formed as unintentional by-products of many industrial processes. The more harmful toxins (dioxins) mainly emanate from industrial processes involving the production of chlorine, although natural process such as volcanoes and forest fires, among other processes are also known to produce dioxins. 2,3,7,8-Tetrachlorodibenzodioxin (2, $3,7,8$-TCDD) is one of the most potent poisons in the dioxin family, classified by the World Health Organisation (WHO) as class one carcinogen. Apart from cancer, even at levels many times lower than those associated with cancer, dioxins are suspected to cause severe human developmental problems including lower sperm count, behavioural problems, immune system damage, among other negative impact. In the current LCA, 1, 4 dichlorobenzene equivalent is used in assessing the processes for the manufacture of 1 tonne of the Spanish and UK products. Results on terrestrial ecotoxicity in Table 7 are presented in graphical form in Figures 9 (a) and (b). The use of the traditional binder materials to stabilise both the Spanish soil (marl) and the UK clay (LOC) show the highest ecotoxicity (Marl + PC; LOC + Lime; LOC + PC). Their poor performance is however lower than the ecotoxicity levels of the concrete block. It is therefore significant to note that both the extraction of aggregates, and binding them with the material sapping, energy-intensive Portland cement, results with highest potential ecotoxicity for the materials considered in the study. The high ecotoxicity can be exacerbated by use of waste in the manufacture process (waste tyres, municipal waste among others), as incineration is also well-known for its share contribution in ecotoxicity.

\section{Conclusions}

The results presented in the current study have confirmed that the establishment of sustainability credentials of emergent construction materials is very subjective. For this reason, most available tools such as BREEAM, CEQUAL, ARUP, SpeAR or ATHENA among others may not necessarily be fully quipped or equipped at all to deal with individual material systems, such as composite cement- or lime-based cementitious systems, including clay-based blocks and bricks. From the work reported in the current study, the following conclusions may be drawn: 
1. The preference of clay-based materials for sustainable construction is justifiable. All the parameters used in the current study have shown that the clay-based materials performed better, per unit strength achieved, than the concrete block. The extraction of aggregates, followed by their binding using the materials sapping and energyintensive Portland cement is perhaps the worst combination in terms for sustainability.

2. Unfired clay systems are further justified, compared with fired clay bricks. While recognising that the unfired systems have much lower performance compared to the fired counterparts, the far higher environmental credentials of the unfired system suggest that more work is needed to identify scope of applicability and limitations of the use of the unfired systems, so as to adopt complementary and synergistic action between the two systems rather than in antagonistic or competing operation.

3. The use of natural, industrial and agricultural waste and by-product materials for partial or whole replacement of the traditional binder materials of lime and/or Portland cement is of significant impact. The impact of this endeavour should not be underestimated. All the parameters used in the current study show over-whelming evidence in favour of this development, despite all the work being a modest replacement level of only $10 \%$. The potential benefits with higher replacement levels of the order of $40 \%$ and above can cumulatively be a game changer for future socioeconomic development.

4. The most challenging aspect in the undertaking of LCA is the availability of reliable input data. The main problems emanate from the audit of each aspect of the material sourcing and processing, and especially the quantification of the relevant transport, energy, environmental (emissions) and other inputs into the composite product. The variability in material ingredients, and lack of base data (emission, energy etc.) for each aspect of the processes involved creates major challenges. Incorporation of materials with long and complex recycling processes further exacerbate the challenge.

5. There is agreement by all the parameters plotted, unanimously suggesting that researchers have many options in parameters for establishing environmental performance depending on capacity, capability, and individual discipline and expertise. Despite all the problems associated with the availability or reliable input data, results show that numerous parameters can reliably be used to assess and to compare different products with/without overemphasis on atmospheric carbon dioxide emissions. The different parameters can be fine-tuned to corroborate different 
503

504

505

506

507

aspects of products manufactured under different conditions, as a way round variable sourcing and complex recycling processes involved in recycling.

6. As overall, sustainably eventually depends on consideration, and the uptake, of individual materials systems, a more focussed address of individual systems and products is needed. 


\section{References}

BS 6073-2:2008, Precast concrete masonry units. Guide for specifying precast concrete masonry units

BS EN 771-1:2011, Specification for masonry units. Clay masonry units

BS EN 197-1:200, Cement. Part 1: Composition, specifications and conformity criteria for common cements

BS EN 15167-2:2006, Ground granulated blast furnace slag for use in concrete, mortar and grout. Definitions, specifications and conformity criteria

CEMBUREAU, 2015. Environmental Product Declaration (EPD) according to EN 15804 and ISO 14025 - Portland-composite cement (CEM II) produced in Europe 1-10.

Chen, C., Habert, G., Bouzidi, Y., and Jullien, A., 2010a. Environmental impact of cement production: detail of the different processes and cement plant variability evaluation. J. Clean. Prod. 18, 478-485. doi:10.1016/j.jclepro.2009.12.014

Chen, C., Habert, G., Bouzidi, Y., and Jullien, A., Ventura, A., 2010b. LCA allocation procedure used as an incitative method for waste recycling: An application to mineral additions in concrete. Resour. Conserv. Recycl. 54, 1231-1240. doi:10.1016/j.resconrec.2010.04.001

EU, E.U., 2008. Directive 2008/98/EC of the European parliament and of the council on waste and repealing certain directives.

European Cement Association (The), 2013. The Role of Cement in the 2050 Low Carbon Economy. (www.cembureau.be/role-cement-2050-low-carbon-economy). 
European reference Life Cycle Database (ELCD), 2016. Life Cycle Inventory (LCI) data from front-running EU-level business associations and other sources for key materials, energy carriers, transport, and waste management. (http://www.eplca.jrc.ec.europa.eu/ELCD3/) accessed on 26/09/2016.)

Flower, D.J.M., and Sanjayan, J.G., 2007. Green house gas emissions due to concrete manufacture. Int. J. Life Cycle Assess. 12, 282-288. doi:10.1007/s11367-007-0327-3

Gala, A.B., Raugei, M., and Fullana-i-Palmer, P., 2015. Introducing a new method for calculating the environmental credits of end-of-life material recovery in attributional LCA. Int. J. Life Cycle Assess. 20, 645-654. doi:10.1007/s11367-015-0861-3

Guinée, J.B., Gorrée, M., Heijungs, R., Huppes, G., Kleijn, R., van Oers, L. W , Sleeswijk, A., Suh, S., Udo de Haes, H.A., de Bruijn, H., vanDuin R , Huijbregts, M.A.J. 2002. Life Cycle Assessment: An Operational Guide to the ISO Standards. Kluwer Academic Publishers. Dordrecht, NL.

Habert, G., D’Espinose De Lacaillerie, J.B., and Roussel, N., 2011. An environmental evaluation of geopolymer based concrete production: Reviewing current research trends. J. Clean. Prod. 19, 1229-1238. doi:10.1016/j.jclepro.2011.03.012

Hammond, G.P., Jones, C.I. 2008. Embodied energy and carbon in construction materials. Proceedings of Institution of Civil Engineers: Energy, 161 (2), 87-98.

Hossain, M.U., Poon, C.S., Lo, I.M.C., and Cheng, J.C.P., 2016. Evaluation of environmental friendliness of concrete paving eco-blocks using LCA approach. Int. J. Life Cycle Assess. 21, 70-84. doi:10.1007/s11367-015-0988-2

ISO, 2006a. ISO 14040 Gestión ambiental Análisis del ciclo de vida Principios y marco de referencia.

ISO, 2006b. ISO 14044 Gestión ambiental Análisis del ciclo de vida Requisitos y directrices. 
ISO, 2007. ISO 14041 Recubrimientos de suelo resilientes, textiles y laminados Características esenciales.

JRC European commission, 2011. ILCD Handbook: Recommendations for Life Cycle Impact Assessment in the European context, Vasa. doi:10.278/33030

Marcelino-Sádaba, S., González-Jaen, L.F., and Pérez-Ezcurdia, A., 2015. Using project management as a way to sustainability. from a comprehensive review to a framework definition. J. Clean. Prod.

Oti, J.E. and Kinuthia, J.M., 2012. Stabilised unfired clay bricks for environmental and sustainable use. Appl. Clay Sci. 58, 52-59. doi:10.1016/j.clay.2012.01.011

Oti, J.E., Kinuthia, J.M., and Bai, J. (2008) Developing unfired stabilized building materials in the UK. Proceedings of the Institution of Civil Engineers (ICE); Journal of Engineering Sustainability, Vol. 161, Issue ES4, pp. 211-218, DOI: 10.1680/ensu.2008.161.4.211.

Oti, J.E., Kinuthia, J.M., and Bai, J. (2009) Engineering properties of unfired clay masonry. Engineering Geology, DOI- 10.1016/j.enggeo.2009.05.002, Volume 107, Issue 3-4, August 2009, Pages 130-139

Pope, J., 2006. What's so special about sustainability assessment? J. Environ. Assess. Policy Manag. v-x.

Schrijvers, D.L., Loubet, P., and Sonnemann, G., 2016a. Developing a systematic framework for consistent allocation in LCA. Int. J. Life Cycle Assess. 1-18. doi:10.1007/s11367-016-1063-3

Schrijvers, D.L., Loubet, P., and Sonnemann, G., 2016b. Critical review of guidelines against a systematic framework with regard to consistency on allocation procedures for recycling in LCA. Int. J. Life Cycle Assess. 21, 1-15. doi:10.1007/s11367-016-1069-x 
Seco, A., Ramírez, F., Miqueleiz, L., Garci, B., and Prieto, E., 2011. The use of nonconventional additives in Marls stabilization. Appl. Clay Sci. 51, 419-423. doi:10.1016/j.clay.2010.12.032

Tait, M.W., and Cheung, W.M., 2016. A comparative cradle-to-gate life cycle assessment of three concrete mix designs. Int. J. Life Cycle Assess. 847-860. doi:10.1007/s11367016-1045-5

The LCI for the materials are based on (CEMBUREAU, 2015; Habert et al., 2011; Oti and Kinuthia, 2012) and data extracted from ELDC (EUROPEAN LIFE CYCLE DATA BASE) http://eplca.jrc.ec.europa.eu/ELCD3/processList.xhtml 


\section{List of Tables}

Table 1 - Oxide composition of PC, PC-8, Lime and GGBS (Spain)

Table 2 - Compositions of different products used in the LCA

Table 3 - The particle size distribution of LOC used in UK products in Table 1. (Oti et al., 2008, 2009).

Table 4 - The oxide composition and other available data for LOC, Lime, GGBS and PC (UK)

Table 5 - Some known physical properties LOC, Lime, GGBS and PC (UK)

Table 6 - Estimated energy used in obtaining the different materials

Table 7 - Life Cycle Analysis (LCA) Results

Table 8 - Acidification potential of selected substances 


\section{List of Figures}

Figure 1 - LCA boundary conditions (Source: Based on ISO 14040)

Figure 2 - LCA system boundary

Figure 3 - Unconfined compressive strength (MPa) of the various brick products from Spain and UK (CB and FCB are controls)

Figure 4 (a) and (b) - Acidification potential $\left(\mathrm{SO}_{2}\right.$ eq. $)$

Figure 5 (a) and (b) - Climate change $\left(\mathrm{CO}_{2}\right.$ eq. $)$

Figure 6 (a) and (b) - Depletion of fossil fuels (MJ)

Figure 7 (a) and (b) - Eutrophication ( $\mathrm{PO}_{4}$ eq.)

Figure 8 (a) and (b) - Ozone layer depletion (CFC)

Figure 9 (a) and (b) - Terrestrial ecotoxicity (kg 1, 4 dichlorobenzene eq.) 